\title{
A Strong Foundation: Inclusive Education at an Australian University College
}

\author{
Tamra Cocks, Jennifer Stokes \\ University of South Australia, Australia
}

\begin{abstract}
As part of a global shift towards widening participation in Higher Education, the Australian Government has established national targets for educational access and social inclusion, resulting in a broader student cohort entering university. This paper will explore the realities of inclusive education, through examining teaching practice in a Foundation Studies program based at an Australian university. Through considering the needs of an increasingly diverse student body, this paper will demonstrate that a supportive program, grounded in teaching academic literacies, can assist students from varied educational backgrounds in successfully transitioning into the university environment and academic culture.
\end{abstract}

\section{Introduction}

In developed nations, a shift is occurring from mass to universal higher education provision and these developments involve a rethink of the exclusive nature of universities and a greater shift from "elitism" to social inclusion" [19]. Widening university participation presents new opportunities for realising inclusive education practice, which acts to ,engage students in learning that is meaningful, relevant and accessible to all ${ }^{\text {ee }}$ [11]. This paper considers the practical challenges of implementing inclusive education, through a case study of an enabling program at an Australian university, which provides a diverse higher education student cohort with access to academia. The paper will discuss the role of enabling programs in preparing students from equity groups for university study, highlighting the merits of a strong, supported foundation.

\section{The Australian context}

Australia's widening participation targets aim to develop the nation as a knowledge economy, while also encouraging greater social inclusion. By 2020, ,20 per cent of undergraduate enrolments in higher education should be students from low socioeconomic backgroundse, with $40 \%$ of $25-34$ year holds holding a bachelor-level degree by 2025 [3]. These targets have seen a renewed focus on equity group enrolments at Australian universities, with many different approaches being taken to enabling programs and different rates of success. A commitment to equity was enshrined in the University of South Australia"es (UniSA ces) founding legislation and this informs institutional values and teaching practice [15]. Supporting this approach, Ross reports that 2010 data identifies ,the University of South Australia as the only institution with 20plus per cent low SES undergraduate recruitment and below-average attrition ratese [20]. This is significantly higher than the 2010 national average of 16.5 per cent [17].

\subsection{UniSA College}

A key part of the UniSA equity strategy is delivered through UniSA College, in the form of academic programs and community engagement activities. The College runs a one year, Commonwealth supported program, called Foundation Studies, which provides a structured, funded transition to university for Australian citizens and certain visa holders. The College also offers two year, HECS-HELP (deferred payment) Diploma programs for those students who have completed secondary studies, but not received a competitive Australian Tertiary Admission Rank (ATAR) for university entry. Foundation Studies requires students to attain a competitive Grade Point Average (GPA) at the end of the year for entry into the university, whereas the Diplomas offer two years of study, after which time students who pass sixteen courses gain entry into the second year of certain degrees. These two programs offer supported entry to university, while also ensuring the quality standards of the university are met by College alumni, who are fully prepared for undergraduate study. The College also works to connect with communities from low-socioeconomic status (low SES) areas in order to present university as an option and to support secondary school students in priority learning areas, such as science, mathematics and the year twelve research project. UniSA College Foundation Studies students come from diverse backgrounds and educational levels. UniSA has taught Foundation Studies since 2006 [15], teaching of Foundation Studies was centralised at UniSA College in 2011 and the Diploma programs were 
opened in 2012. The Diploma cohort only entered the College in 2012, so limited data is available. There are currently over 750 students at the College [2]. Overall College student numbers reflect the significant demand for enabling programs in the South Australia, with enrolment numbers on track to exceed 2017 projections in 2013 [2].

The Foundation Studies cohort comprises many students coming from one or more of the government defined equity groups; „ATSI (Aboriginal and Torres Strait Islanders), " Disability"e, „Isolated"e, „Low-socio economic statuse (Low- SES), „NonEnglish-Speaking Background (NESB) and „Rural ${ }^{\text {ee }}$ [15]. In fact, data collected over 2006-2008 showed that, „55\% of Foundation Studies students came from at least one of these equity groups, compared to the $42.5 \%$ institutional average representation of most equity groups is generally higher in Foundation Studies, indicating that the program is effective in providing second-chance opportunities to access HE for people who have experienced educational disadvantage $^{\text {ee }}$ [15]. Once these students have enrolled in the Foundation Studies program, extended support is provided to ensure increased likelihood of successful transition into university. While equity groups are at a greater risk of exiting the HE system, the pass rates of low SES students who remain in the system are stable and on par with other demographics, attaining ,97 per cent of the pass rates of their medium and high socio-economic status peers $^{\text {ee }}$ [3]. The College is working particularly well to support students from low-SES backgrounds, who comprise $50 \%$ of the current College cohort, and students from NESB, who comprise $20 \%$ of the College cohort [2].

\section{The Foundation Studies program}

Foundation Studies aims to prepare students for university study, teaching academic literacies, academic culture and program specific knowledge in a supportive environment. The majority of College student enrolments are in this fee-free program which carries minimal financial risk for those who wish to test their aptitude for university study. At the completion of Foundation Studies, students use their GPA to apply for competitive entry into undergraduate studies. 2011 student records shows the effectiveness of this approach, as $45-50 \%$ of completers went on to undergraduate study in 2012 [2], including a number of highly successful students who entered the university's flagship degrees, such as law, physiotherapy, journalism and medical radiation science. Klinger and Murray [16] note that retention in access programs is usually 50\%; UniSA College retention at $79 \%$, based on available statistics [2], is significantly above the norm.

While granting access to $\mathrm{HE}$ is one of UniSA Collegees main goals, ensuring these students are prepared and equipped with academic literacies is paramount for their retention. According to the Intersegmental committee of the Academic Senates [12], determining a student ${ }^{\text {ee }} \mathrm{s}$ competency and readiness for tertiary study cannot be decided on a list of skills; it is in the stages of preparing for more advanced academic work when a student"s learnt behaviours and perceptions reflect true academic competence. Students need to be guided through this transition by supportive teaching staff as they develop the academic literacies required, such as selecting appropriate research topics, understanding how to search for quality sources and building convincing, academic arguments. UniSA College teaching staff aim to minimise the „culture shock ${ }^{\text {ee }}$ [7] and vulnerability students feel as first-year undergraduates by focusing not only on course content, but also teaching academic etiquette, such as communication methods and behaviours, that will ease their transition into an academic environment.

There are a large number of Foundation Studies students who come from educationally disadvantaged backgrounds, who have not had the opportunity to access tertiary study programs before and, therefore, are unfamiliar with a university setting. Ramburuth and Härtel [19] explain that students from low-SES backgrounds may feel that their identities are devalued in comparison to those of high status social identity leading them to seek „identify-safe ${ }^{e e}$ environments where they feel welcomed and supported. UniSA College is designed to offer a non-threatening learning environment for these students who may otherwise feel daunted by the first-year undergraduate experience. In establishing an inclusive college community, students not only learn and gain supports from staff but also from their peers. Encouraging students to be actively involved in a new academic learning environment, builds learner confidence and inspires them to participate, while instilling a sense of belonging to a college community that evidently cares about their academic future. This in turn significantly reduces feelings of vulnerability and enables learners to reconstruct their social identities [10]. UniSA College ${ }^{e c}$ inclusive teaching practice is designed to maximise student engagement, creating greater opportunities for the students to extend academic literacies. A supported transition to university must elucidate university expectations and offer students a sense of belonging within the HE environment, allowing them to fully become part of academic culture. To achieve this transition, Bennett and Burgess argue that enabling education must clearly articulate the hidden academic curriculum, „without reducing the level of engagement so much that students already familiar with "academic and intellectual" materials are isolated, working with the course material so that all students can decide what is at first an incomprehensible field of academic 
language and conventions, is an important pedagogical component in this setting ${ }^{\text {ee }}[1]$.

The foreign culture of the university can be difficult to navigate and ,support through familiarity with higher education ${ }^{\text {ee }}$ is often missing for students from equity groups [1]. Enabling programs need to ensure that course content embeds strategies for managing university studies and understanding academic culture. Foundation Studies aims to provide a supported transition by making explicit the rules and culture of the institution, so that students are aware of the policies, guidelines and attitudes which govern behaviour within the university space. While university may appear less restrictive than other educational institutions, it is important for students to recognise that there are codes of behavior in place, which are founded in respect for others and creating an environment in which learning and intellectual growth can occur. It is also important for students to understand that breaching these codes is not tolerated. This awareness will help ensure that students do not transgress the rules inadvertently. Inclusive teaching practice provides benefits for all students by clearly identifying expectations and offering ,induction into specific discourses and epistemic constructions of knowledge in academic

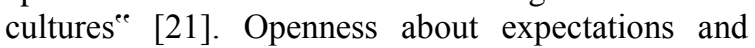
values is part of building trust and helping students to understand academic culture. This aspect of academic literacy can be embedded in core courses, assisting students in successfully negotiating tertiary study.

\section{Designing inclusive curriculum}

Foundation Studies is designed as an inclusive, student-centred program in order to develop academic literacies. A constructivist approach is used, allowing students to build on existing knowledge and supporting diverse cohorts to engage with university content; as Gale notes ,socially inclusive teaching is about providing room for different ways of thinking about, and different ways of engaging with knowledge, and indeed including different kinds of understandings that perhaps have not been part of Australian higher education before ${ }^{\text {ee }}$ [9]. Teaching is scaffolded throughout the year, so that students receive extensive additional support during the start of the program, allowing them a chance to build trust and good study practice. Curriculum is designed to assist students in developing their abilities as autonomous, adult learners throughout the program, allowing a smooth transition to undergraduate studies. Staff assists students in fostering a commitment to their studies; „once low socioeconomic status students are in university, it is essential to nurture their learner

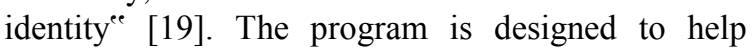
students develop academic literacies through core courses which focus on; research strategies, essay writing, critical thinking, English language, sociopolitical knowledge, group work and information technology. The students then choose to specialise in study areas relevant to their preferred undergraduate degree, such as health sciences and mathematics, building prerequisite knowledge in a supported environment. The course examples below demonstrate how inclusive teaching is embedded in practice.

\subsection{A scaffolded approach}

A supported transition to university learning is embedded throughout the curriculum year, as illustrated in two complementary courses: Introduction to Tertiary Learning (ITTL) in semester one and Information Skills in semester two. ITTL is a compulsory course which aims to orient commencing students to the university environment, through building the skills to write a 1500 word research essay. This course explicitly focuses on academic literacies, such as conducting research, referencing and essay writing, while also developing academic skill sets such as tutorial participation and managing stress. Students appreciate the scaffolded approach, identifying the best aspects of the course as, ,getting the student from essentially having little to no knowledge of what is required in essay writing, researching, and referencing amongst other essentials to tertiary learning, to a level in which they can do this independently without assistance as well as assisting others with problems they may be havinge [6]. Students may then elect to study Information Skills in the second semester, which provides an opportunity to extend their ability to source relevant information and critically analyse texts. On completion of this course, students produce a 2000 word research essay, reflecting a developed academic understanding of a chosen topic. Through completing this course, students develop skills and confidence as adult learners, „fantastic way to teach us how to learn. After doing this course I am confident to continue in an undergraduate course with the tools I need to successfully research. I also loved that we could choose our own topics and research, it allows us to explore future study areas and that knowledge will again help out next year' [6]. This scaffolded transition to university-level work is supported by Cantwell, who notes that Foundation Studies programs encourage the student to engage in and develop high level cognitive processes [5].

\subsection{NESB and academic literacies}

NESB students in higher education programs where English is the main language of instruction encounter additional challenges related both to 
language and culture, which has a significant impact on their acquisition of academic literacy. Kasper asserts, ,although becoming multi-literate is not an easy task for any student, it is especially difficult for ESL students operating in a second language. In their attempts to become multi-literate, ESL students must acquire linguistic competence in a new language and at the same time develop the cognitive and sociocultural skills necessary to gain access into the social, academic, and workforce environments of the 21 st century ${ }^{\text {ee }}[14]$.

77 of the 403 enrolled Foundation Studies students in 2011 identified as ESL students and were enrolled in the course English Language Studies for Second Language Learners of English [2]. This curriculum has been devised to provide intensive English language support as well as the development of critical thinking skills. The course develops the students $^{\text {ee }}$ understanding of how the use of the English language differs in social and academic contexts. Furthermore, it gives students insight into the relationship between language and culture.

Understanding how language is used differently in various contexts is not only important for students $^{\text {ee }}$ development of English language proficiency but also to further build upon their understanding of their new academic culture. Encouraging student interaction and participation throughout the course is fundamental in the acquisition of the students ${ }^{\text {ce }}$ language skills. Therefore activities are scaffolded and designed to be interactive so that students can support and learn from one another. All efforts are made to build students ${ }^{\text {ee }}$ confidence and encourage contributions in class activities. Engstrom and Tinto explain how this is important in a college environment, ,many students explained that in the past they were afraid to speak in class and participate fully in the learning process, especially in high school. The learning community experience was different because people got to know each other, trusted and respected each other, took risks, and really participated....This was particularly important for students whose first language was not English. ESL students emphasized how scared and anxious they were and how participation in the collaborative environment of the learning community helped them to overcome their fear"e [8].

Student comments have demonstrated how the course has assisted them with language and academic literacy skills, ,the PowerPoint presentations and teaching methods are perfect. The best aspect of the lecturer was that she understood all students ${ }^{\text {ee }}$ needs. She gave feedback and made every lecture clear by clarifying the topic with the entire class ${ }^{\text {ee }}[6]$.

\section{Access with support}

The diverse nature of the student cohort and the additional vulnerability many students from equity groups face in higher education means that these students require additional support. As Engstrom and Tinto [8] argue, ,access without support is not opportunitye, therefore a significant feature of enabling programs must be to provide students with ongoing opportunities to establish connections with academic support services and develop good practices which will assist throughout their studies. Foundation Studies connects students to support services in many ways, from presence of support staff at orientation to embedded material within course content. Regular meetings between teaching staff and academic support staff allow a more responsive approach to student needs; for example scheduling timely workshops on managing stress around major assignment deadlines. Specific individual support is also available through the campus $^{\text {ee }}$ Learning and Teaching Unit which offers meetings with Learning Advisors, Counsellors, Careers Advisors and Disability Advisors. Students with disabilities are encouraged to disclose early, so that they can be connected to appropriate support services and technology, in order to gain the most beneficial outcomes. Academic staff also have regular drop-in times for student consultation, so that students are able to easily find and speak with academics regarding assignments, course content and other issues. This regular access to a wide range of learning supports helps to assist students with both academic and other issues.

Staff are motivated by a commitment to equitable access to education and genuine concern for student progress, informing a commitment to supporting students to succeed. Academic staff are accessible on campus at designated times, ensuring that students are able to easily meet with and discuss issues with lecturers. This time also provides an opportunity for students to have drafts read and to seek particular advice about assignment ideas, or clarification of course concepts. The accessibility of the lecturers reflects their classification as „Teaching focused ${ }^{\text {ee }}$ meaning that student learning is the priority of their role. Academic support staff are also available to meet with students to provide enrolment support and course counselling, playing an important role in assisting students to make informed choices about their studies. In this way, the staff and students at UniSA College are united by a sense of purpose and a concern for the progress of the students. Staff awareness of student needs has resulted in extensive support being made available to students.

Academic Literacy Support workshops have been provided for the large number of students coming from NESB. However the workshops have also been regularly attended by those ESB students who lack 
confidence in carrying out academic reading and writing tasks, due to a long absence from educational institutions. Inexperience with academic texts has prompted many students to seek additional guidance and tuition with their assignments and value the workshop support highly; „my last full year of education was in 1988, year 9 high school! Consequently I have needed special assistance to reenter the tertiary system, to understand the course work, and just exactly what is required of me. This is where the weekly workshops have been especially valuable to mee [6]. The aims of the workshops are to provide intensive support in developing students ${ }^{\text {ee }}$ reading and writing skills. The literacy teacher works collaboratively with other college lecturers to incorporate program relevant material. For example, the workshops may focus on a particular course reading or look at how to research for and structure course assignments. Students are encouraged to share any particular literacy concerns they may have. Any specific concerns are addressed by structuring the workshops to suit the identified needs.

In addition to English language workshops, there are weekly supports sessions available for most content areas. Students are advised of the weekly time slot, and then can visit the available tutor to gain advice and support on numeracy, computing, essay writing and general study practices. Learning Advisors from the Learning and Teaching Unit are also available in the Student Common Room, to offer additional support each week.

Enabling programs can assist students in making informed choices regarding undergraduate study by embedding information about degree options and providing chances to connect with Career Services and other information sites within the university. A bias toward specific professions is evident in the number of students who wish to become teachers, midwives, and nurses, arguably the universityqualified positions which they have experienced the most real-world contact with. Enabling programs need to provide students with chances to consider their interests in greater detail within a university context, so that they can be connected with the most appropriate undergraduate degree. This broadening of perspectives enables a wider range of aspirations. For example, the student who wished to be a science teacher finds a preference for urban planning, while the student who aspired to become a nurse considers occupational therapy. Further to this, some students undertake enabling programs with a limited understanding of the actual requirements of their desired degree; for example the student who wishes to undertake Media Studies assuming there will be limited reading involved, or the student who is keen to study Law, but is terrified of public speaking.

These students would benefit from academic counsel prior to applying for degree programs, to ensure that their expectations are realistically aligned with the commitment they are able to make to their studies. In this way, enabling programs can offer students a chance to broaden their study options and assist students in finding the most applicable program for their interests.

For those students who receive significant benefit from the supportive environment of the College, the Diploma programs offer the option of an extended supported transition to undergraduate studies. Students who commence Diploma programs take the Foundation Studies courses at the College in first year, and then enrol in first year degree courses within selected schools of the university in their second year of the Diploma, while also receiving weekly support sessions with Diploma Program Directors and also having access to all of the support services that the College provides. While students need an ATAR to apply to the Diploma programs in the first instance, those who are completing Foundation Studies may apply to the second year of the Diplomas, if they would like to continue their studies with an additional year of support from the College. In this way, the Diplomas offer an additional supportive option for students as they connect with the broader university.

\section{The challenges}

While the university has supplementary support systems in place, the complex needs of such a diverse student cohort can be difficult to anticipate. UniSA College students come from a variety of educational, linguistic and socio-cultural backgrounds. Addressing this diversity of learning needs presents challenges for staff.

\subsection{NESB cohort}

In the teaching of NESB domestic students some ethical issues become apparent. Approximately a quarter of enrolled Foundation Studies students identify as NESB. Minimal entry requirements allow all NESB students admittance into the program regardless of their language capabilities. The absence of an English language entrance test makes it near impossible to identify students with critically low proficiency levels. In contrast, minimum entry requirements for international students undertaking Foundation Studies programs in other Australian institutions specify that they must have attained English language proficiency comparable to an overall score of 5.5 in the International English Language Testing System (IELTS) or equivalent [18]. Yet, based on the observations of UniSA College academic staff, some NESB students ${ }^{\text {ce }}$ proficiency levels would fall well below 5.5. Interestingly, most English language entry requirements for international students wishing to 
enter undergraduate level are, ,typically a score of 6 to 6.5 on the IELTS test. Even this standard has been criticised as barely adequate for university study by a number of researchers ${ }^{\text {ee }}$ [4].

Under current enrolment conditions, it is not until after teaching commences that NESB students in Foundation Studies with particularly low proficiency levels are identified. Despite having an English Language Studies course and Academic Literacy support workshops on offer, these students struggle with course tasks and assignments because they are still building upon their understanding of basic grammar form and developing coherent sentence structures. Therefore they encounter difficulties in carrying out fundamental reading and writing tasks, and inevitably lag behind their peers, unable to keep up with course tasks and understand key concepts. Bretag argues, ,while second language learners master basic interpersonal communication skills within a relatively short period of time, ...these students need to develop cognitive academic linguistic proficiency (CALP) if they are to succeed in academic second language learning contexts, particularly at the tertiary level. Research over the last 25 years indicates that it takes between five and ten years to develop CALPe [4]. Therefore it is reasonable to conclude that a proportion of NESB students at the College are so disadvantaged by their poor language capabilities that they have little chance of passing the Foundation Studies program, let alone have the minimum proficiency level for entering undergraduate studies. While it may seem contradictory to the principles of enabling education programs, implementing an English language entry test may be the best way of filtering students who are clearly not at the minimum proficiency level necessary for academic coursework. The current policy seems to be encouraging unrealistic expectations of academic achievement in some NESB students despite having very limited language skills. It would seem more appropriate for these students to enrol in an English language school first.

The diversity of English language proficiency presents another challenge for course design as there is only room for one English language course in the program. The students ${ }^{\text {ee }}$ English proficiency levels range from low to upper intermediate with some displaying more competency than others in one of the four skills: speaking, listening, reading and writing. Assessment tasks, lectures and tutorial activities need to be carefully structured so that all students, regardless of their English capabilities, are able to gain positive learning outcomes. However serving such diverse learning needs is not an easy task, therefore raising questions about the purpose of the course. Is the aim to prepare the students for undergraduate level and equip them with academic reading and writing skills, or to design a course that builds upon their grammatical knowledge and develops their communicative competence? Either way, some students will feel isolated as the course tasks and assessment items may not match their specific aptitudes. Academic staff must also keep in mind that the development of Academic English language skills is an issue that affects students from ESB (English speaking backgrounds). Assuming that ESB students have sufficient grammatical knowledge and are confident with academic reading and writing tasks is erroneous. Ensuring that English language support is available to both NESB and ESB students is important in order not to show favour or discriminate towards one group.

\subsection{Transitioning into academic culture}

Another challenge associated with students new to university culture is teaching the importance of adhering to academic conventions. Students from different cultural and educational backgrounds must adjust to university academic integrity expectations. Therefore, practical academic integrity lessons, such as explaining why Wikipedia is not a reliable university standard information source, or why plagiarising is a serious breach of academic conduct, are embedded throughout the program. Providing students with plagiarism avoidance strategies is especially necessary for those disadvantaged by low English language proficiencies. Academic staff are explicit in advising students how to apply paraphrasing and referencing skills to their assignments. However, irrespective of reemphasising the application of these skills, NESB students with basic reading and writing skills can still fall into the trap of plagiarising pieces of text and inadvertently omitting vital references. With only basic literacy skills and a misunderstanding of the gravity of the situation, some of these students may compromise their academic integrity.

In most cases, it is not until a student is contacted by the College Academic Integrity Officer (AIO) that they realise they have engaged in academic misconduct. Some students can experience distress once they understand the university's stance on such transgressions. For this reason, all investigations of academic integrity breaches are treated sensitively. The AIO assumes an educative rather than punitive role by re-explaining academic integrity concepts and demonstrating to the students how to properly acknowledge sources and avoid plagiarising sections of text. In some instances, students are referred to Language Learning Advisors to build upon their skills in these academic conventions. Generally most students do not breach academic integrity again as they are mindful of applying these skills in other assessment tasks. Foundation Studies provides students with opportunities to become familiar with university norms, expectations and workload. Here, the teacher's role is to ,help students understand why 
others view the world in a different way ${ }^{\text {ee }}$ [22]. Like any new culture, students need time to adapt to the rules of etiquette within that new learning environment. For example, students can misunderstand that it is unacceptable to make late requests for extensions. Learning how to communicate in a polite, formal register and becoming a considerate member of a learning community are important steps in transitioning into this new academic culture. A key role of Foundation Studies is training students to work within university expectations and timelines so that they can succeed in undergraduate study.

\subsection{Trauma (humanitarian students)}

A proportion of the students enrolled at the College are classified as Humanitarian Visa holders. Some of these students have sought asylum in Australia after surviving considerable trauma in their home country. In some cases, students carry the burden of worrying about family members still located in areas of conflict. Emotional distress caused by harrowing experiences in the home country and constant concern for loved ones still living in these areas can affect the students' general wellbeing and their engagement with academic study.

Refugee students, who were interviewed as part of a case study by Joyce et al. [13], expressed how feelings of anxiety and concern for family members back home have a huge impact on their concentration levels at university. In these cases, academics aim to direct students to counselling services to ensure that their emotional wellbeing is supported first, allowing them to be able to focus on study. The College staff at times can feel overwhelmed by the nature and number of these distressing cases. Therefore, staff also need additional support and services to manage complex student needs. At the College, educative workshops have been provided by counselling staff, so that staff are more aware of and better able to manage the complex needs of students from humanitarian backgrounds. The Employee Assistance Program also provides support for staff, to minimize secondary trauma. Refugee students can also face pressure to succeed in their academic study due to unrealistic expectations placed upon them by family members. At times there is a misconception amongst the parents of these students that their child will succeed in the Foundation Studies program earning a high grade point average which will inevitably gain them entry into a flagship degree program. High expectations are common amongst this cohort despite the students ${ }^{\text {ee }}$ unprecedented experience with Western education systems, poor English language skills and other work and family responsibilities to contend with. The College academic staff observes the pressure these students are under and at times can feel pressured by the students to pass them with high grades. Staffs are currently designing a „Parents and Friends Information Session ee to help communicate realistic expectations of university study.

Adapting to a new academic culture and understanding how Western education systems operate can also present major challenges for refugee students. The orientation stage can span over months as students grow accustomed to becoming an autonomous learner. Participants in a case study conducted by Joyce's et.al [13] commented on the significant differences in education styles between Australia and in their home country. The students felt they had been immersed in a new academic culture which places emphasis on self-directed learning. They had to quickly grow accustomed to new assessment procedures and tasks. Staff at the College is mindful that refugee students may experience this type of acculturation process more poignantly than other students, which has informed the development of current support systems. Furthermore, the academic staff maintains flexibility in their teaching practice to be inclusive of a variety of learning styles.

\section{Conclusion}

UniSA College Foundation Studies program is part of one university ${ }^{\text {ee }}$ response to Australia's national equity targets. Rapid increases in enrolments and high retention rates suggest that this transition model is effective and serves a particular need for supporting students from equity groups, particularly those from NESB and low-SES backgrounds. This paper has explored some of the practical challenges of providing inclusive university education to an increasingly diverse student body. With any new cohort challenges will arise; however, where there is an institutional commitment to inclusive education, staff are better able to develop strategies to support student needs. Extended support systems are necessary to accommodate more vulnerable learner identities. Furthermore, informed and caring university staff are better able to identify and respond to student specific learning needs. A supportive learning environment, which recognizes both the academic and social impact of university, can equip students with the requisite academic literacies, and help them develop a passion for intellectual engagement. A thorough foundation studies program can effectively prepare students for the rigours of undergraduate study by providing time to develop as autonomous learners and offering a supported transition to academic culture. 


\section{References}

[1] Bennett, A. and Burgess, C. (2011), „Challenges at the cultural interface: the hidden academic cultural curriculume, in 1st International Australasian Conference on Enabling Access to Higher Education conference proceedings, Adelaide, Australia, pp. 60- 69.

[2] Boyle, S. (2012) Selected student equity statistics for enrolment in 2011 and 2012, UniSA College, Adelaide.

[3] Bradley, D., Noonan, P., Nugent, H. \& Scales, B. (2008) Review of Australian Higher Education, Commonwealth of Australia, Australia.

[4] Bretag, T. (2007), „The emperores sew clothes: yes, there is a link between English language competence and academic standards"e, People and Place, vol. 15, no.1, pp. 13-21.

[5] Cantwell, R. (2004), „Positioning the bar: Outcomes associated with successful completion of an enabling course $^{e e}$, Australian Journal of Adult Learning, vol. 44, no. 3, pp. 354-388.

[6] CEIs and SETs 2009-2011, University of South Australia, Adelaide.

[7] Christie, H., Tett, L., Cree, V., Hounsell, J. \& McCune, V. (2008) „A real rollercoaster of confidence and emotion "e: learning to be a university student", Studies in Higher Education, vol. 33, no. 5, pp. 567-581.

[8] Engstrom, C. \& Tinto, V. (2008), „Access without support is not opportunity"e, Change, vol. 40, no.1, pp. 4650.

[9] Gale, T. (2010) 2010 Occasional papers on learning and teaching at UniSA, Paper 2: Towards socially inclusive teaching and learning in higher education, University of South Australia, Adelaide, Australia.

[10] Gallacher, J., Crossan, B., Field, J. \& Merrill, B. (2010) „Learning careers and the social space: exploring the fragile identities of adult returners in the new further education"e, International Journal of Lifelong Education, vol. 21 , no. 6 , pp. 493-509.

[11] Hockings, C. (2010) Inclusive Learning and Teaching: Research Synthesis, Higher Education Academy, York.

[12] Intersegmental Committee of the Academic Senates, (2002) Academic Literacy: a statement of competencies expected of students entering California"s public colleges and universities, Intersegmental Committee of the Academic Senates, Sacramento.

[13] Joyce, A., Earnest, J., De Mori, G. \& Silvagni, G. (2009) ,The experiences of students from refugee backgrounds at universities in Australia: reflections on the social, emotional and practical challenges"e, Journal of Refugee Studies, Vol. 23, No. 1, pp. 82-96.

[14] Kasper, L. (2000) „New technologies, new literacies: focus discipline research and ESL learning communities"e, Language Learning \& Technology, vol. 4, no. 2, pp. 105128.

[15] Klinger, C. \& Murray, N. (2011) „Access, aspiration and attainment: Foundation Studies at the University of South Australia, International Perspectives on Higher Education Research, vol. 6, pp. 137-146.

[16] Klinger, C. \& Murray, N. (2012) „Tensions in higher education: widening participation, student diversity and the challenge of academic language/literacy"e, Widening Participation and Lifelong Learning, vol. 14, no. 1, pp. 2744.

[17] Lomax-Smith, J., Watson, L. \& Webster, B. (2011) Higher Education Base funding Review: Final Report 2011, Commonwealth of Australia, Australia.

[18] National Standards for Foundation Programs (2009) Australian Education International, viewed 16th January $2012<$ http://www.aei.gov.au/regulatoryinformation/ Education-Services-for-Overseas-StudentsESOS-LegislativeFramework/foundationstandards/Pages/Default.aspx>.

[19] Ramburuth, P. \& Härtel, C. (2010) „Understanding and meeting the needs of students from low socioeconomic status backgroundse, Multicultural Education and Technology Journal, vol. 4, no. 3, pp. 153-162.

[20] Ross, J. (2011) „Bradley Targets threatened by high drop-out rates among disadvantaged students" ${ }^{\text {ee }}$ Australian, September 14, viewed December 20, 2011 <http://www.theaustralian.com.au/highereducation/ bradley-targets-threatened-by-high-drop-outratesamong-disadvantaged-students/story-e6frgcjx1226136074420>

[21] Warren, D. (2002) „Curriculum design in a context of widening participation in higher education ${ }^{\text {ee }}$ Arts and Humanities in Higher Education, vol. 1, no. 1, pp. 85-99. [22] Wintergerst, A. \& McVeigh, J. (2011) Tips for Teaching Culture: Practical Approaches to Intercultural Communication, Pearson, New York. 